\title{
TSE pathogenesis in cattle and sheep
}

\author{
Lucien J.M. van Keulen*, Alex Bossers, Fred van ZiJderveld
}

\author{
Department of Bacteriology and TSE's, Central Institute for animal Disease Control (CIDC), Wageningen \\ University and Research Centre, PO Box 2004, 8203 AA Lelystad, the Netherlands
}

(Received 27 April 2007; accepted 9 November 2007)

\begin{abstract}
Many studies have been undertaken in rodents to study the pathogenesis of transmissible spongiform encephalopathies (TSE). Only a few studies have focused on the pathogenesis of bovine spongiform encephalopathy (BSE) and scrapie in their natural hosts. In this review, we summarize the most recent insights into the pathogenesis of BSE and scrapie starting from the initial uptake of TSE agents and crossing of the gut epithelium. Following replication in the gut-associated lymphoid tissues (GALT), TSE agents spread to the enteric nervous system (ENS) of the gut. Infection is then carried through the efferent fibers of the post-ganglionic neurons of the parasympathetic and sympathetic nervous system to the pre-ganglionic neurons in the medulla oblongata of the brain and the thoracic segments of the spinal cord. The differences between the pathogenesis of BSE in cattle and scrapie in sheep are discussed as well as the possible existence of additional pathogenetic routes.
\end{abstract}

prion / $\mathrm{PrP}^{\mathrm{Sc}}$ / scrapie / bovine spongiform encephalopathy (BSE) / pathogenesis

Table of contents

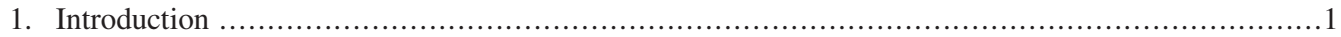

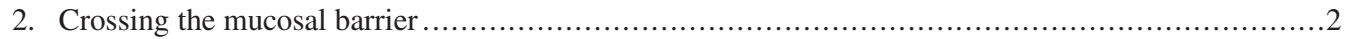

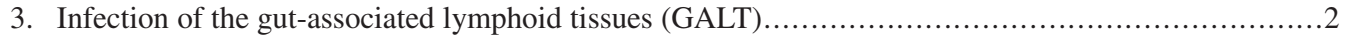

4. Draining to the GALT lymph nodes and lymphatic/haematogenic dissemination .......................

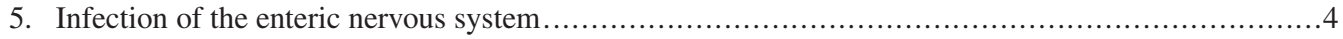

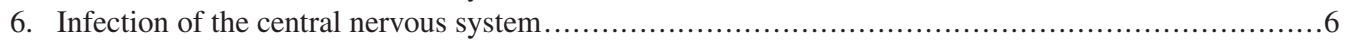

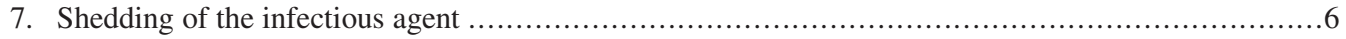

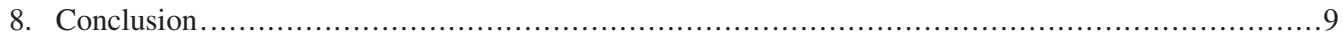

\section{INTRODUCTION}

Although scrapie has been known for decades, relatively little attention has been paid to it as a natural disease of sheep and goats mainly because the economical impact has been relatively small compared to other diseases in sheep. The occurrence of bovine spongiform encephalopathy (BSE) in cattle provided a new impetus to research into the transmissible spongiform encephalopathies (TSE) [70]. Not only was

\footnotetext{
*Corresponding author: lucien.vankeulen@wur.nl
}

the economical impact of BSE much greater than that of scrapie, the link with variant Creutzfeldt-Jakob disease (vCJD) in humans also gave rise to serious concerns regarding food safety [9].

In most of the recent TSE research, (transgenic) mice and hamsters have been used to study the pathogenesis of TSE $[1,4,15,38$, $50,62]$. Few studies have been undertaken to study the pathogenesis of TSE in the natural host. Hadlow et al. [22, 23] were among the first to study scrapie as a natural disease in sheep. At that time, there was no knowledge 
yet on the relationship between the susceptibility for scrapie and the PrP genotype of sheep. Nevertheless, they succeeded in providing the first insights into the pathogenesis of natural scrapie using the classical but cumbersome mouse bio-assay to detect scrapie infectivity. They showed that scrapie infectivity first accumulated in the lymphoid tissues of the alimentary tract before gaining access to other lymphoid tissues and finally the central nervous system $[22,23]$. Led by these results, they postulated that the most likely way of infection of the central nervous system (CNS) was through blood, even though infectivity had never been detected in blood of sheep with natural scrapie.

Today, we know far more about scrapie susceptibility and its relationship with $\mathrm{PrP}$ genotype [5-7, 28, 29, 31, 40]. In addition, we now have many different techniques to detect $\mathrm{PrP}^{\mathrm{Sc}}$ as a marker for scrapie infectivity $[37,43,46$, $47,52,60]$. In particular $\mathrm{PrP}^{\mathrm{Sc}}$ immunohistochemistry has been very useful in pathogenesis studies, as it offers the additional advantage of revealing the cellular and neuro-anatomical localization of $\mathrm{PrP}^{\mathrm{Sc}}$ in the tissues thereby providing valuable information on the neuroanatomical pathways.

Previous immunohistochemical studies on clinical cases of scrapie have given some clues about possible pathogenetic routes of the scrapie agent to the brain. For instance, it had been noted before that the dorsal motor nucleus of the nervus vagus (DMNV) was exceptionally heavily immunolabelled for $\mathrm{PrP}^{\mathrm{Sc}}$ compared to other neuro-anatomical nuclei $[2,64]$. Moreover, in some early cases of scrapie the DMNV was sometimes found to be the only nucleus in the brain which was positive for $\mathrm{PrP}^{\mathrm{Sc}}$. In conjunction with the discovery of $\mathrm{PrP}^{\mathrm{Sc}}$ in the enteric nervous system of sheep with scrapie, a possible pathogenetic route was postulated [66]. However, sequential time point studies in sheep and cattle were still required to finally resolve the important issues in the pathogenesis of TSE. In this review, we summarize the most recent results of the various pathogenesis studies of natural scrapie in sheep and BSE in cattle.

\section{CROSSING THE MUCOSAL BARRIER}

Infection of sheep and cattle by TSE agents occurs through the oral route although scarification of the skin and infection of (damaged) mucous membranes/conjunctiva are suggested as alternative routes of infection [45, 58, 61]. In scrapie, the infectious agent is present in the environment and taken up orally during grazing on scrapie contaminated pastures $[8,13,14]$. In the case of BSE in cattle, infection has occurred through feeding concentrates with meat and bone meal derived from BSE infected cattle [75-77]. It is still obscure how TSE agents cross the mucosal barrier after they are ingested but there are three possible ways (Fig. 1). The first is through the M-cells, a cell type present in the follicle-associated epithelium of the gut and tonsil which specializes in transport of macromolecules and particles across the epithelium [24]. It has been shown for prions, viruses (reovirus, poliovirus, and human immunodeficiency virus), and bacteria (Mycobacterium avium subsp. paratuberculosis, Salmonella species, Yersinia species Campylobacter jejuni, Vibrio cholerae, and Shigella flexneri) that M-cells can be used by pathogens to cross the mucosal barrier and gain access to the underlying tissues [48]. However, transport of TSE agents across the gut epithelium could also occur independent of M-cell transport. Digestive enzymes can break down the infectious agent into smaller molecules of $\mathrm{PrP}^{\mathrm{Sc}}$ or even into the protease resistant core of $\mathrm{PrP}^{\mathrm{Sc}}$. Such smaller fragments can then form complexes with other proteins like ferritin and get endocytosed in vesicular structures by a ferritin dependent mechanism [44]. A third possible route could be through direct uptake by dendritic cells that can open up the tight junctions between epithelial cells and capture antigens by inserting their dendritic processes into the gut lumen $[54,55]$. This had been demonstrated for bacteria but has yet to be shown for TSE agents.

\section{INFECTION OF THE GUT-ASSOCIATED LYMPHOID TISSUES (GALT)}

After crossing the mucosal barrier, infectivity and $\mathrm{PrP}^{\mathrm{Sc}}$ first accumulates in the 


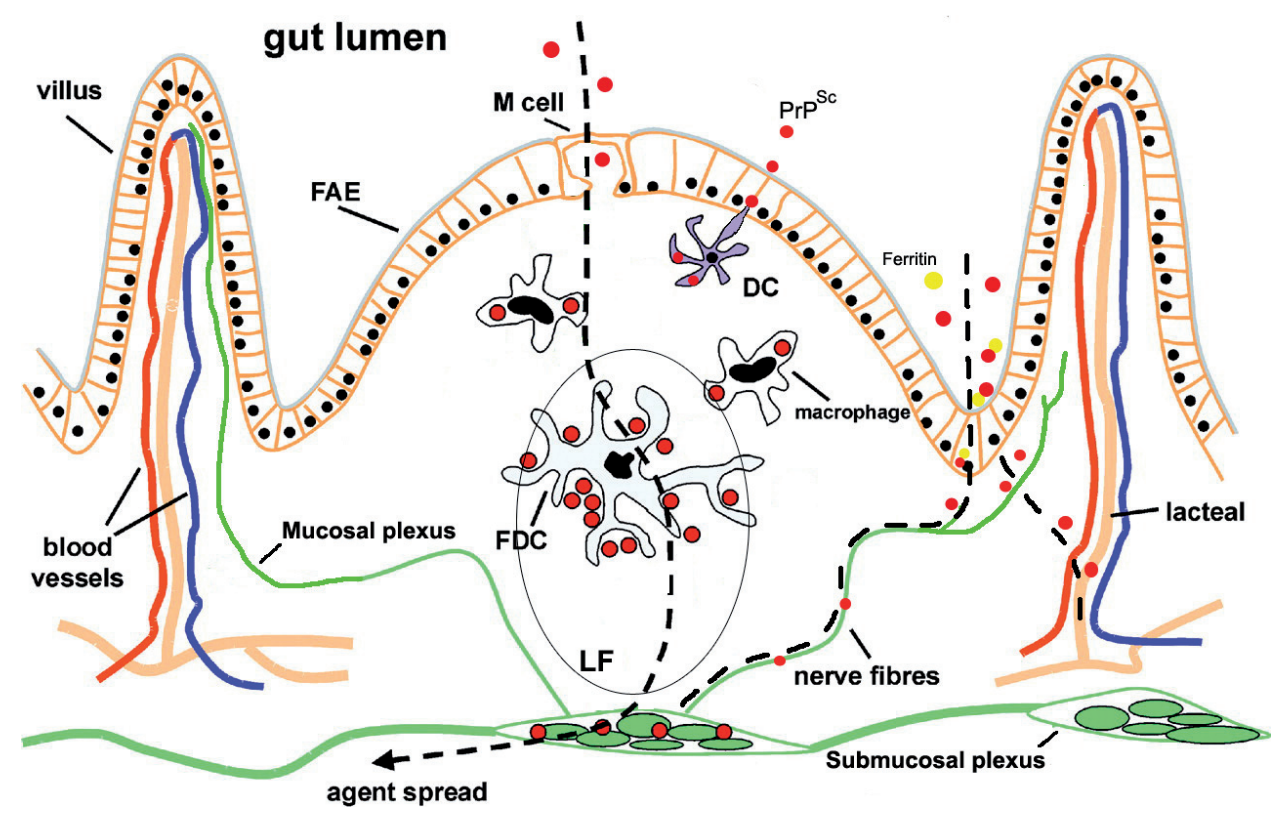

Figure 1. Schematic representation of the possible ways of intestinal epithelial crossing and subsequent invasion of the ENS. After ingestion, $\operatorname{PrP}^{\mathrm{Sc}}$ can be taken up by M-cells or dendritic cells and transported to the lymphoid follicles (LF) of the Peyer's patches underlying the follicle-associated epithelium (FAE). Within the lymphoid follicles $\mathrm{PrP}^{\mathrm{Sc}}$ accumulates on follicular dendritic cells and is taken up by follicular macrophages. This accumulation of $\operatorname{PrP}^{\mathrm{Sc}}$ could facilitate infection of the neighbouring submucosal plexus of the ENS. Alternatively, $\operatorname{PrP}^{\mathrm{Sc}}$ could be taken up as a complex with ferritin and transcytosed by intestinal epithelial cells through the ferritin pathway. Once the epithelium is crossed, the mucosal plexus of the ENS can get infected followed by neural spread to the submucosal plexus.

gut-associated lymphoid tissues (GALT) of the tonsil and the Peyer's patches in the intestines $[2,23,68]$. This initial accumulation in the GALT strongly favors the hypothesis of transport of TSE agents through M-cells because antigens that have been transcytosed by M-cells are actively transported from the basal side of the M-cells to the underlying GALT by either dendritic cells or macrophages.

The first immunohistochemical evidence of $\mathrm{PrP}^{\mathrm{Sc}}$ in the GALT consists of the intracellular accumulation within the tingible body macrophages (TBM) in the B-cell follicles. At a later stage, $\operatorname{PrP}^{\mathrm{Sc}}$ is also found on the plasmalemma of the follicular dendritic cells (FDC) in the germinal centres of the B-cell follicles [2, 35, 65, 67]. The replication of the TSE agents in the GALT is thought to be crucial to the further neuro-invasion as disease susceptibility is reduced in experimental animal models in which FDC function is impaired [10,42]. However, absence of agent replication in the GALT does not fully prevent neuro-invasion. For instance in sheep of the VRQ/ARR PrP genotype (carrying both the VRQ allele associated with high scrapie susceptibility and the ARR allele associated with high scrapie resistance) there is minimal or no involvement of the lymphoid tissues in agent replication [65]. However, these sheep do get natural scrapie, albeit at an older age [7]. In addition, they can be experimentally infected when the oral dose of scrapie agent is high enough ${ }^{1}$.

In cattle, replication of the BSE agent in the lymphoid tissues is minimal to absent.

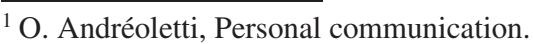


In naturally infected $\mathrm{BSE}$ cases no $\mathrm{PrP}^{\mathrm{Sc}}$ has been detected in the lymphoid system [32,63], while infectivity could only be demonstrated in the Peyer's patches of the ileum by bio-assay in highly BSE-sensitive transgenic mice carrying the bovine PrP allele (and not in non-transgenic mice) $[11,20]$. In cattle experimentally infected with a high oral dose of BSE, infectivity was present in the ileum six months after oral infection $[71,73]$ and in the tonsil ten months after oral infection (the latter only detectable using the more sensitive bovine transgenic mouse and cattle bioassay) $[16,74]$. In these animals $\operatorname{PrP}^{\mathrm{Sc}}$ was immunohistochemically detected in TBM of the ileal Peyer's patches but not in the tonsil $[26,63,74]$. Despite this apparently low involvement of the lymphoid system, neuroinvasion still occurs after a relatively long incubation period.

\section{DRAINING TO THE GALT LYMPH NODES AND LYMPHATIC/HAEMATOGENIC DISSEMINATION}

After replication in the GALT, the scrapie agent is drained to the GALT draining lymph nodes. This means that for the tonsil, TSE agents are drained to the retropharyngeal lymph node and for the Peyer's patches to the mesenteric lymph nodes $[2,68]$. At this stage, $\mathrm{PrP}^{\mathrm{Sc}}$ can be detected immunohistochemically in cells in the subcapsular sinuses indicating to a cellular transport from the GALT to the GALT draining lymph nodes. In addition, $\mathrm{PrP}^{\mathrm{Sc}}$ can be seen to accumulate on FDC and in TBM of the lymphoid follicles in the cortex of the GALT lymph nodes. Surprisingly, no $\mathrm{PrP}^{\mathrm{Sc}}$ has ever been described in cells of the medullary sinuses although TSE agents are further disseminated from the GALT to other lymphoid tissues outside the GALT. It is still unknown whether this further dissemination of the scrapie agent through lymph and blood occurs by an active cellular transport, or in a free state possibly bound to some component in the lymph or blood plasma. Scrapie infectivity in blood has long been a subject of much debate. Many studies have failed to demonstrate scrapie infectivity in the blood or blood frac- tions $[22,23,25]$ but, with the aid of recent more sensitive techniques, $\operatorname{PrP}^{\mathrm{Sc}}$ has been detected in blood of sheep with scrapie $[33,57]$. Furthermore, sheep blood transfusion studies (which are basically intravenous sheep bio-assays) have shown that scrapie can be transmitted from a scrapie positive donor to a susceptible scrapie free recipient. This can be done with whole blood or, in the end stage of clinical scrapie, with buffy coat from the scrapie affected donor [30]. Scrapie infectivity in blood could be a feature throughout much of the course of the disease or it could be an intermittent or transient phenomenon.

In cattle with BSE, no other sites of agent replication or $\operatorname{PrP}^{\mathrm{Sc}}$ accumulation have been found in the lymphoid tissues apart from the GALT tissues of the Peyer's patches in the ileum and the tonsil of experimentally infected animals $[11,16,20,32,72-74]$. Infectivity is also not detectable in the blood of BSE affected cows with the mouse bio-assay $[16,72]$. Even intracerebral inoculation of buffy coat from orally infected BSE donors into calves (cattle bio-assay) has failed to demonstrate BSE infectivity in this blood component ${ }^{2}$. This would indicate the absence of a lymphatic or haematogenic spread of BSE in cattle, which is in agreement with the lack of infectivity and $\mathrm{PrP}^{\mathrm{Sc}}$ in the non-GALT lymphoid tissues.

\section{INFECTION OF THE ENTERIC NERVOUS SYSTEM}

The first neural tissues in which $\mathrm{PrP}^{\mathrm{Sc}}$ can be demonstrated both in sheep scrapie and cattle BSE is the enteric nervous system (ENS) of the gut $[2,32,67]$. The ENS is the intramural nervous system of the gut and is composed of two major networks or plexuses which contain the neuronal cell bodies (also called ganglion cells) and their processes. These two major plexuses are the submucosal or Meissner's plexus located in the submucosa, and the myenteric or Auerbach's plexus located between the circular and longitudinal muscle layers (extending from the esophagus to the rectum) (Fig. 2). In addition to these two major plexuses there are minor plexuses in the

\footnotetext{
${ }^{2}$ G.A.H. Wells, Personal communication.
} 


\section{Parasympathetic}

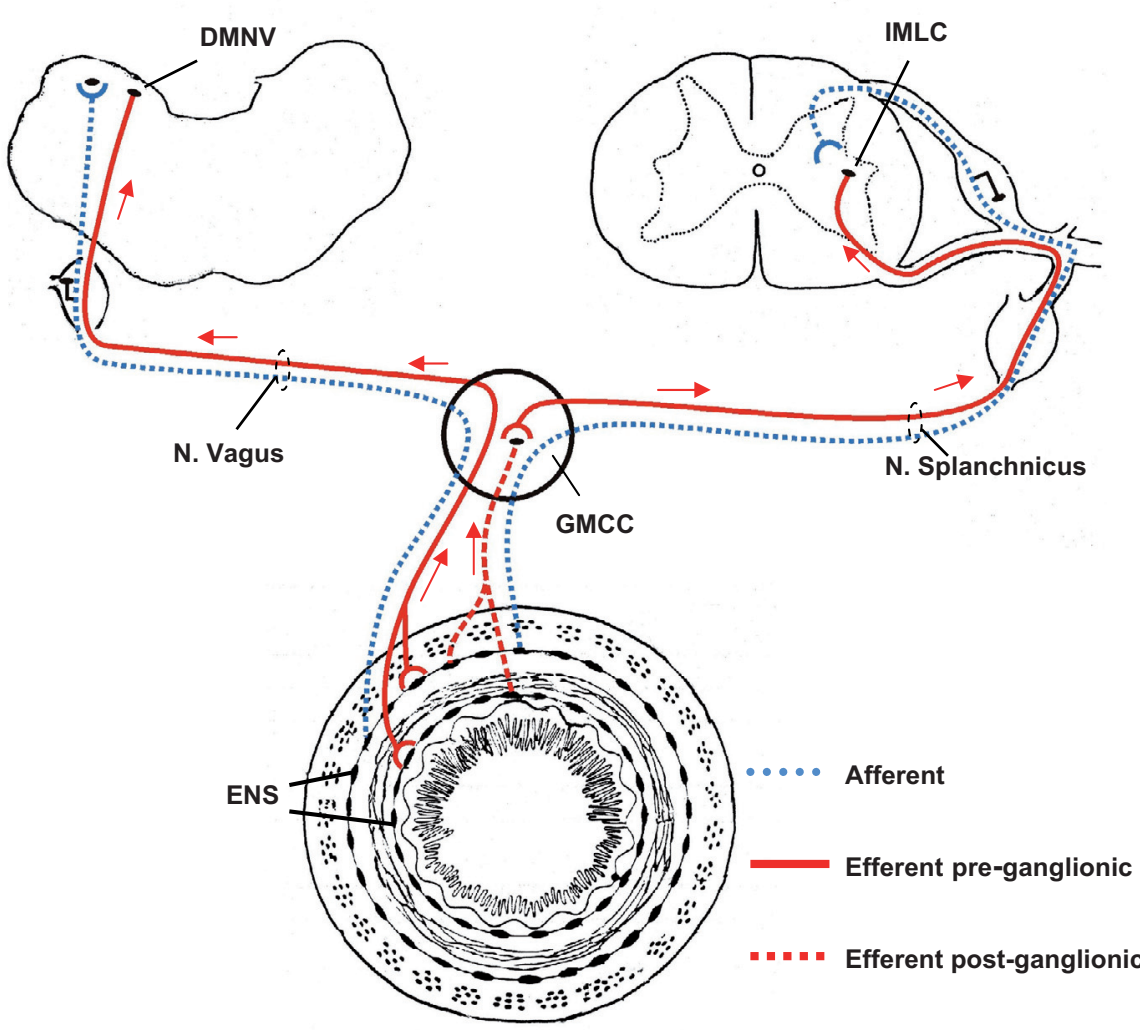

Sympathetic

Figure 2. Schematic representation of the parasympathetic (shown on the left) and sympathetic (shown on the right) innervation of the enteric nervous system (ENS). The cell bodies of the parasympathetic efferent nerve fibers are located in the dorsal motor nucleus of the vagus (DMNV) in the medulla oblongata (preganglionic) and in the enteric nervous system (ENS) within the gut wall (post-ganglionic); cell bodies of the sympathetic efferent nerve fibers are located in the intermediolateral column (IMLC) in the spinal cord (pre-ganglionic) and in the ganglion mesentericum cranialis/coeliacum (GMCC) (post-ganglionic). The afferent parasympathetic nerve fibers have cell bodies in the ganglion nodosum (GN) and terminate in the nucleus tractus solitarius (NTS). The cell bodies of the afferent sympathetic fibers are located in the ganglia spinalis (GS). Reproduced with permission from van Keulen et al. [67].

serosa, circular muscle layer, and in the mucosa that contain no or few ganglion cells but consist mainly of small nerve fibers [21].

Infection of the ENS could theoretically take place at different levels (Fig. 1). After crossing the mucosal barrier (either through M-cells or transepithelially), TSE agents can come into contact with the fine nerve fibers of the mucosal plexus of the ENS directly underneath the villous epithelium [34]. However, it is equally possible that TSE agents can in- fect the submucosal plexus of the ENS after they have been transported from the epithelium to the Peyer's patches in the submucosa. No direct nerve endings from the ENS have been demonstrated in/or around B-cell follicles of the Peyer's patches, but infection could occur through some other means of contact between the Peyer's patches and the ENS, either through active cell transport or drainage via lymph/tissue fluid. Neuro-invasion of the submucosal plexus of the ENS is probably 
facilitated by the replication of TSE agents in the neighbourhing Peyer's patches but is not a prerequisite for neuro-invasion as demonstrated in VRQ/ARR scrapie sheep and in BSE in cattle.

In a study of natural sheep scrapie, the duodenum and the ileum were identified as the initial sites of the gut ENS invasion [67]. The scrapie agent then spreads cranially and caudally within the ENS to involve other parts of the small intestine and at a later stage even the ENS of the esophagus, forestomachs, large intestine, and rectum (Fig. 3).

\section{INFECTION OF THE CENTRAL NERVOUS SYSTEM}

Although the ENS is capable of functioning independently, it is modulated by the central nervous system (CNS) by means of the parasympathetic and sympathetic efferent nerves of the autonomic nervous system that are connected to the enteric plexi. The cell bodies of the preganglionic parasympathetic neurons are located in the DMNV in the medulla oblongata while the preganglionic sympathetic neurons lie within the intermediolateral column (IMLC) in the spinal cord (Fig. 2) [36]. After infection of the ENS, TSE agents ascends through these parasympathetic and sympathetic efferent neuronal pathways to the brain and (via the ganglion mesentericum craniale/coeliacum) to the spinal cord [26, 67]. Portal of entry of TSE agents in the brain is thus the DMNV in the medulla oblongata at the level of the obex and the IMLC in the thoracic segments of the spinal cord. From these sites in the CNS, infection spreads in both an ascending and descending direction to finally involve the entire neuraxis (Fig. 3).

The observations of initial ENS infection and spread through autonomic efferent nerve fibers do not preclude other possible routes of neuro-invasion. Theoretically it is also possible that the scrapie agent travels to the CNS through other peripheral nerve endings originating from infected non-GALT lymphoid tissues. Another possible route to the CNS would be through haematogenic spread during the phase of scrapie infectivity in the blood. In a study of natural scrapie in VRQ/VRQ sheep, $\operatorname{PrP}^{\mathrm{Sc}}$ was found as amyloid within capillary endothelial cells in the hypothalamus at the age of 14 months, when $\mathrm{PrP}^{\mathrm{Sc}}$ within neurons and glial cells was still restricted to the DMNV in the medulla oblongata at the level of the obex, and in the IMLC in the thoracic segments of the spinal cord [67]. This form of $\mathrm{PrP}^{\mathrm{Sc}}$ deposition could indicate to a haematogenic infection of endothelial cells during scrapie infection, but is unlikely to play an important role in neuro-invasion. A useful model to study possible additional pathogenetic routes of the scrapie agent to the CNS is sheep carrying the VRQ/ARR genotype. As mentioned earlier these sheep can develop scrapie in the CNS without prior replication in the lymphoid tissues. Direct experimental inoculation of scrapie into various lymphoid tissues or directly into the bloodstream has not provided any indications yet as to the existence of additional neuro-invading routes (unpublished results).

\section{SHEDDING OF THE INFECTIOUS AGENT}

In BSE of cattle all the evidence indicates that under natural conditions the BSE agent does not spread horizontally into the environment by any secreta or excreta or vertically through maternal transmission; in other words for BSE cattle are a dead-end host $[12,78]$. The cycle of infection that caused the BSE epidemic has been established through human intervention by the rendering of BSE-infected carcasses and feeding the produced meat and bone meal to cattle. Breaking this cycle has had a tremendous effect on the incidence of BSE which dramatically declined after banning meat and bone meal for the production of animal food.

Contrary to BSE in cattle, scrapie is an endemic disease meaning that the scrapie agent does transmit between sheep under natural conditions. Epidemiological studies suggest that the scrapie agent spreads horizontally either by direct contact between animals or through contamination of the environment. Despite the fact that infectivity has been never been found in any secreta or excreta of scrapie 
a)

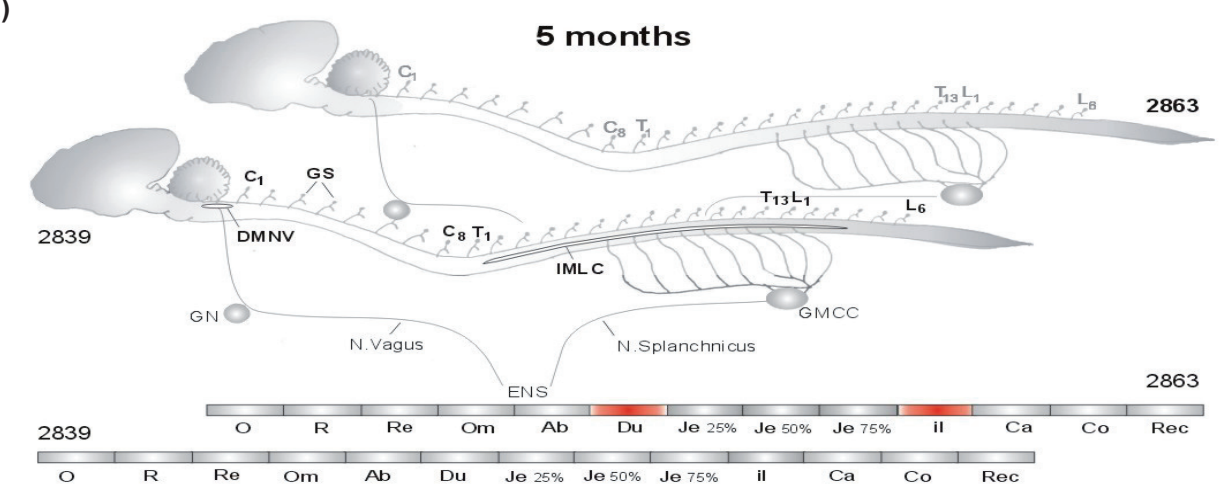

b)

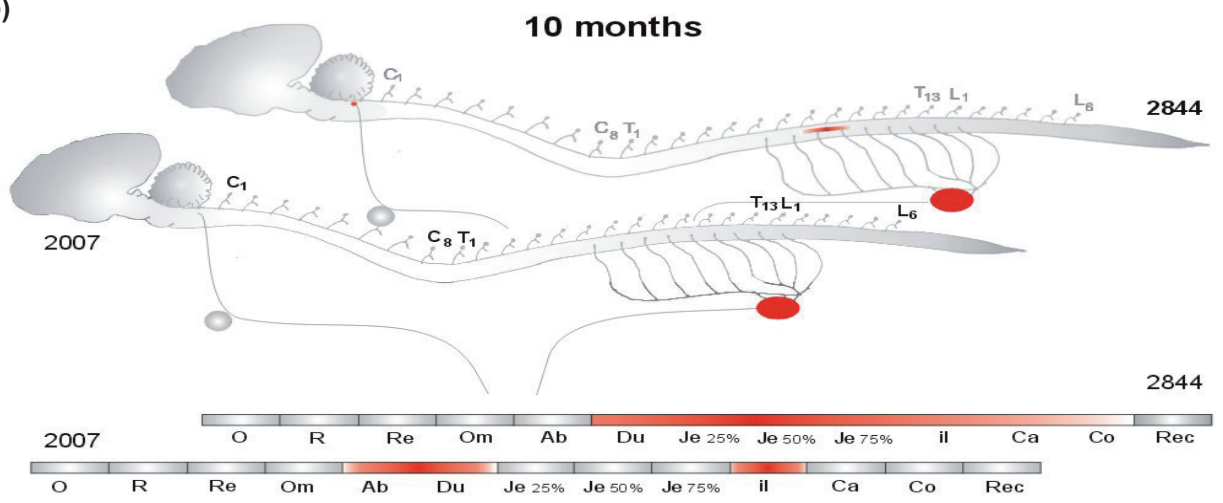

c)

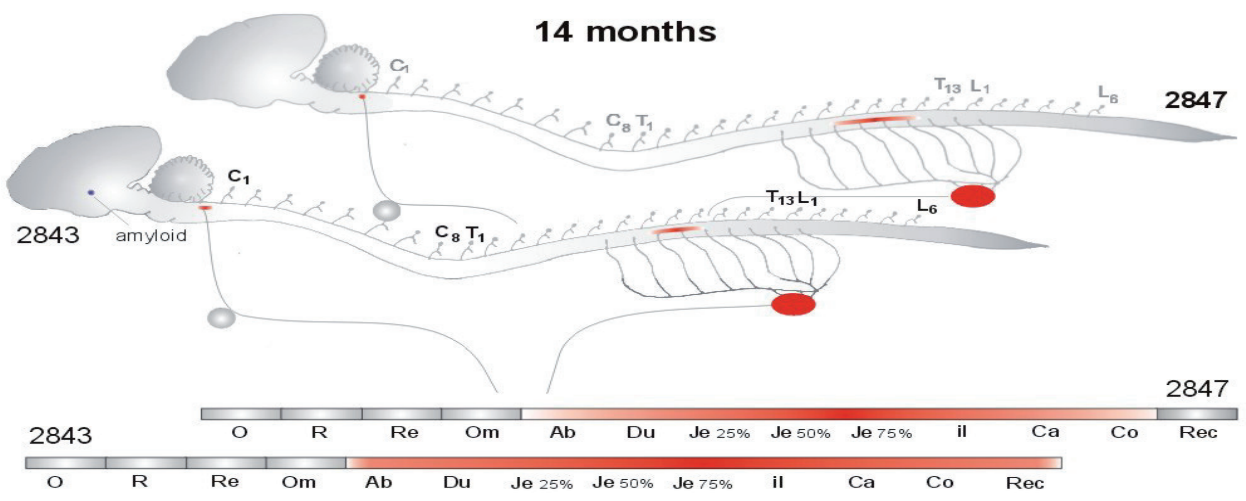

Figure 3. Schematic representation of $\mathrm{PrP}^{\mathrm{Sc}}$ accumulation (in red) in the ENS and CNS in naturally scrapieaffected sheep of the VRQ/VRQ genotype at (a) 5 months; (b) 10 months; (c) 14 months; (d) 17 months; (e) 21 months; and (f) 26 months of age. DMNV - dorsal motor nucleus of the vagus; IMLC - intermediolateral column; C, T, and L - cervical, thoracic, and lumbal segments of the spinal cord; GN - ganglion nodosum; GMCC - ganglion mesentericum cranialis/coeliacum; GS - ganglia spinalis; O - oesophagus; $\mathrm{R}$ - rumen; $\mathrm{Re}$ - reticulum; $\mathrm{Om}$ - omasum; $\mathrm{Ab}$ - abomasum; Du - duodenum; Je - jejunum; il - ileum; $\mathrm{Ca}$ - caecum; $\mathrm{Co}$ - colon; $\mathrm{Rec}$ - rectum. Animal numbers are indicated on the left and on the right: the ENS and CNS of the same animal are aligned to the left or to the right. Only efferent nerve fibers are shown. (Reproduced with permission from van Keulen et al. [67]). 
d)

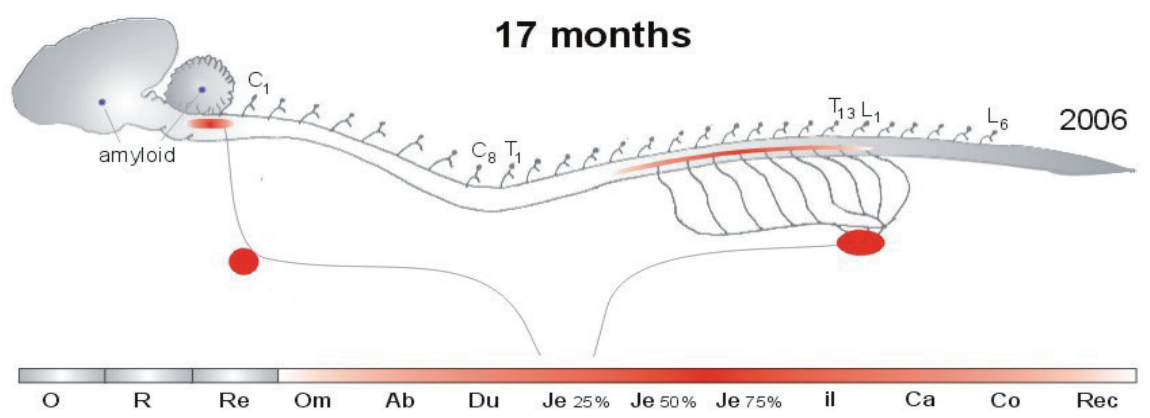

e)

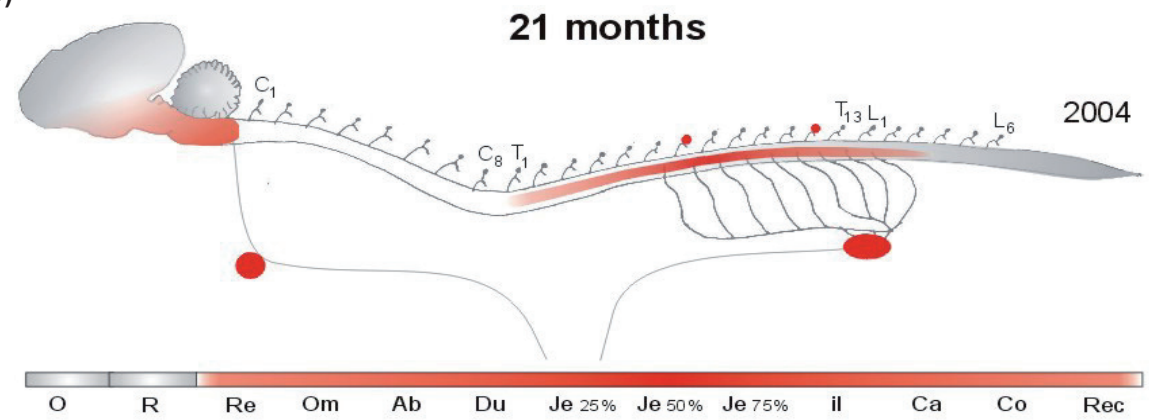

f)

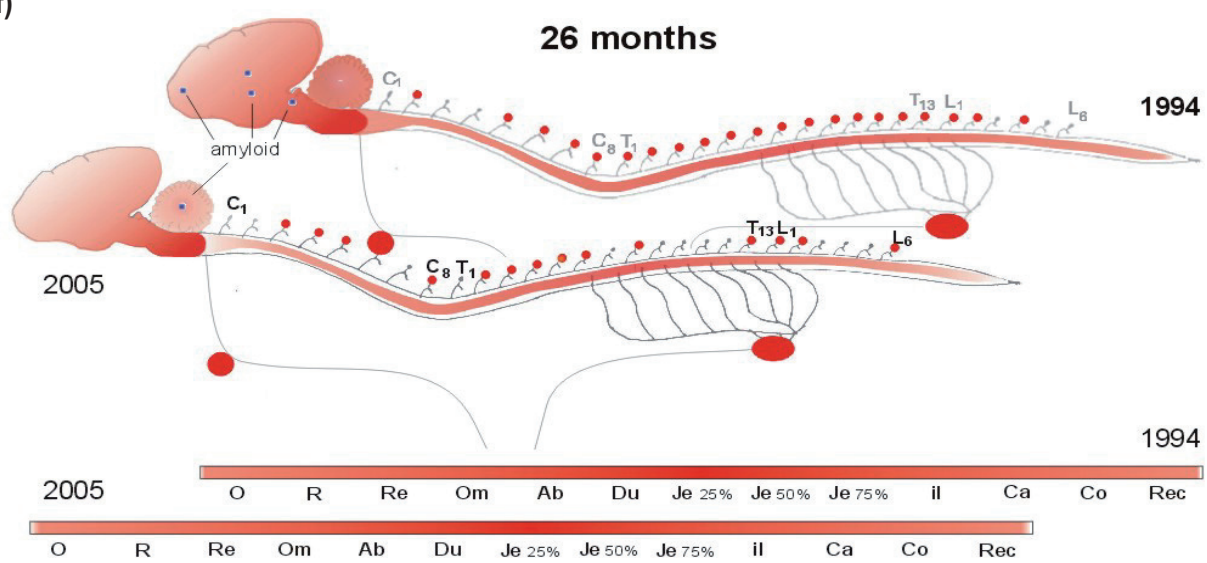

Figure 3. Continued.

infected sheep (reviewed in [27]), it does not exclude possible low levels of infectivity in milk, saliva, faeces, or urine of scrapieinfected sheep. $\mathrm{PrP}^{\mathrm{Sc}}$ detection in ectopic lymphoid tissue in the mammary gland [41], in the renal papillae [59], and in the salivary glands of scrapie-infected sheep [69] have raised questions about the possible role of milk, urine, and saliva in the transmission of scrapie.

There is less controversy about the role of the placenta in the transmission of scrapie. 
Infectivity and $\mathrm{PrP}^{\mathrm{Sc}}$ have been detected in the fetal part of the placenta $[3,8,13,39,49,51$, $53,56]$ which is shed after lambing. Infectivity is thus spread into the environment causing a rather efficient horizontal transmission to other sheep (or goats) with susceptible PrP genotypes. Offspring of scrapie-infected ewes is also most likely infected through horizontal transmission after birth rather than through vertical, in utero transmission [17-19,27]. Recent studies have elucidated the mechanism involved in scrapie replication in the placenta [3]. $\operatorname{PrP}^{\mathrm{Sc}}$ only accumulates in the trophoblast cells of the chorionic epithelium (= the fetal part of the placenta) when there is a dissemination of the scrapie agent in the blood of a ewe. Hence, no $\operatorname{PrP}^{\mathrm{Sc}}$ accumulation could be found in placentae of fetuses carried by VRQ/ARR dams. In addition to the required infectivity in the blood of the dam, the PrP genotype of the fetus (and thus the PrP genotype of the fetal placenta/chorionic epithelium) must be of a susceptible PrP genotype. Only if both conditions are met, can the scrapie agent replicate in the fetal placenta [39].

\section{CONCLUSION}

Over the last few years, more TSE research has focussed on sheep and cattle as the natural hosts of TSE. The pathogenesis of scrapie in sheep and BSE in cattle is more similar than first expected at least with respect to the crucial role that the sympathetic and parasympathetic efferent fibers of the autonomic nervous system play in the neural spread of TSE agents from the enteric nervous system to the brain and the spinal cord. However, with respect to the lymphatic spread of TSE agents there is an important difference between scrapie in sheep and BSE in cattle which accounts for the differences in transmission dynamics. In cattle with BSE the involvement of the lymphoid system is restricted to the GALT and no infectivity is spread into the environment, making cattle a dead-end host for BSE. In sheep with scrapie, however, haematogenic dissemination of the scrapie agent causes infection of all lymphoid tissues (except in the VRQ/ARR genotypes) as well as the fetal part of the placenta (only from lambs with a susceptible PrP genotype). When the placenta is shed after lambing, scrapie infectivity can spread into the environment thereby closing the circle of infection for scrapie as an endemic disease in sheep.

\section{REFERENCES}

[1] Aguzzi A., Pathogenesis of spongiform encephalopathies: an update, Int. Arch. Allergy Immunol. (1996) 110:99-106.

[2] Andréoletti O., Berthon P., Marc D., Sarradin P., Grosclaude J., van Keulen L., Schelcher F., Elsen J. M., Lantier F., Early accumulation of $\mathrm{PrP}(\mathrm{Sc})$ in gutassociated lymphoid and nervous tissues of susceptible sheep from a Romanov flock with natural scrapie, J. Gen. Virol. (2000) 81:3115-3126.

[3] Andréoletti O., Lacroux C., Chabert A., Monnereau L., Tabouret G., Lantier F., Berthon P., Eychenne F., Lafond Benestad S., Elsen J.M., Schelcher F., $\operatorname{PrP}(\mathrm{Sc})$ accumulation in placentas of ewes exposed to natural scrapie: influence of foetal PrP genotype and effect on ewe-to-lamb transmission, J. Gen. Virol. (2002) 83:2607-2616.

[4] Beekes M., McBride P.A., Baldauf E., Cerebral targeting indicates vagal spread of infection in hamsters fed with scrapie, J. Gen. Virol. (1998) 79:601-607.

[5] Belt P.B.G.M., Bossers A., Schreuder B.E.C., Smits M.A., PrP allelic variants associated with natural scrapie, in: Gibbs C.J.J. (Ed.), Sixth International Workshop on bovine spongiform encephalopathy: the BSE dilemma, Springer-Verlag, New York, USA, 1995, pp. 294-305.

[6] Belt P.B.G.M., Muileman I.H., Schreuder B.E.C., Bos-de Ruijter J., Gielkens A.L.J., Smits M.A., Identification of five allelic variants of the sheep PrP gene and their association with natural scrapie, J. Gen. Virol. (1995) 76:509-517.

[7] Bossers A., Schreuder B.E.C., Muileman I.H., Belt P.B.G.M., Smits M.A., PrP genotype contributes to determining survival times of sheep with natural scrapie, J. Gen. Virol. (1996) 77:2669-2673.

[8] Brotherston J.G., Renwick C.C., Stamp J.T., Zlotnik I., Spread of scrapie by contact to goats and sheep, J. Comp. Path. (1968) 78:9-17.

[9] Bruce M.E., Will R.G., Ironside J.W.W., McConnell I., Drummond D., Suttie A., McCardle L., Chree A., Hope J., Birkett C.R., Cousens S.N., Fraser H., Bostock C.J., Transmissions to mice indicate that 'new variant' CJD is caused by the BSE agent, Nature (1997) 389:498-501.

[10] Bruce M.E., Brown K.L., Mabbott N.A., Farquhar C.F., Jeffrey M., Follicular dendritic cells in TSE pathogenesis, Immunol. Today (2000) 21:442-446.

[11] Buschmann A., Groschup M.H., Highly bovine spongiform encephalopathy-sensitive transgenic mice 
confirm the essential restriction of infectivity to the nervous system in clinically diseased cattle, J. Infect. Dis. (2005) 192:934-942.

[12] Curnow R.N., Hau C.M., The incidence of bovine spongiform encephalopathy in the progeny of affected sires and dams, Vet. Rec. (1996) 138:407-408.

[13] Dickinson A.G., Stamp J.T., Renwick C.C., Maternal and lateral transmission of scrapie in sheep, J. Comp. Pathol. (1974) 84:19-25.

[14] Dickinson A.G., Scrapie in sheep and goats, in: Kimberlin R.H. (Ed.), Slow virus diseases of animals and man, North Holland Publishing Company, Amsterdam, the Netherlands, 1976, pp. 209-241.

[15] Eklund C.M., Kennedy R.C., Hadlow W.J., Pathogenesis of scrapie virus infection in the mouse, J. Infect. Dis. (1967) 117:15-22.

[16] Espinosa J.C., Morales M., Castilla J., Rogers M., Torres J.M., Progression of prion infectivity in asymptomatic cattle after oral bovine spongiform encephalopathy challenge, J. Gen. Virol. (2007) 88:1379-1383.

[17] Foster J., McKenzie C., Parnham D., Drummond D., Goldmann W., Stevenson E., Hunter N., Derivation of a scrapie-free sheep flock from the progeny of a flock affected by scrapie, Vet. Rec. (2006) 159:42-45.

[18] Foster J.D., McKelvey W.A., Mylne M.J., Williams A.E., Hunter N., Hope J., Fraser H., Studies on vertical transmission of scrapie in sheep and BSE in goats using embryo transfer, in: Bradley R., Marchant B. (Eds.), Transmissible spongiform encephalopathies. A consultation on BSE with the Scientific Veterinary Committee of the Commission of the European Communities held in Brussels, 14-15 September 1993, Brussels, Belgium, 1993, pp. 229-259.

[19] Foster J.D., Hunter N., Williams A.E., Mylne M.J., McKelvey W.A., Hope J., Fraser H., Bostock C., Observations on the transmission of scrapie in experiments using embryo transfer, Vet. Rec. (1996) 138:559-562.

[20] Fraser H., Foster D., Transmission to mice, sheep and goats and bioassay of bovine tissues, in: Bradley R., Merchant B. (Eds.).Transmissible spongiform encephalopathies. A consultation on BSE with the Scientific Veterinary Committee of the Commission of the European Communities held in Brussels, 14 15 September 1993, Brussels, Belgium, 1993, pp. 145159.

[21] Furness J.B., Costa M., The enteric nervous system, Churchill Livingstone, Edinburgh, UK, 1987.

[22] Hadlow W.J., Race R.E., Kennedy R.C., Eklund C.M., Natural infection of sheep with scrapie virus, in: S.B. Prusiner, W.J. Hadlow (Eds.), Slow transmissible diseases of the nervous system, New York, USA, 1979, pp. 3-12.

[23] Hadlow W.J., Kennedy R.C., Race R.E., Natural infection of Suffolk sheep with scrapie virus, J. Infect. Dis. (1982) 146:657-664.
[24] Heppner F.L., Christ A.D., Klein M.A., Prinz M., Fried M., Kraehenbuhl J.P., Aguzzi A., Transepithelial prion transport by M cells, Nat. Med. (2001) 7:976977.

[25] Herrmann L.M., Baszler T.V., Knowles D.P., Cheevers W.P., $\operatorname{PrP}(\mathrm{Sc})$ is not detected in peripheral blood leukocytes of scrapie-infected sheep: determining the limit of sensitivity by immunohistochemistry, Clin. Diagn. Lab. Immunol. (2002) 9:499-502.

[26] Hoffmann C., Ziegler U., Buschmann A., Weber A., Kupfer L., Oelschlegel A., Hammerschmidt B., Groschup M.H., Prions spread via the autonomic nervous system from the gut to the central nervous system in cattle incubating bovine spongiform encephalopathy, J. Gen. Virol. (2007) 88:1048-1055.

[27] Hoinville L.J., A review of the epidemiology of scrapie in sheep, Rev.-Off. Int. Epizoot (1996) 15:827852 .

[28] Hunter N., Goldmann W., Benson G., Foster J.D., Hope J., Swaledale sheep affected by natural scrapie differ significantly in PrP genotype frequencies from healthy sheep and those selected for reduced incidence of scrapie, J. Gen. Virol. (1993) 74:1025-1031.

[29] Hunter N., Goldmann W., Smith G., Hope J., The association of a codon 136 PrP gene variant with the occurrence of natural scrapie, Arch. Virol. (1994) 137:171-177.

[30] Hunter N., Foster J., Chong A., McCutcheon S., Parnham D., Eaton S., MacKenzie C., Houston F., Transmission of prion diseases by blood transfusion, J. Gen. Virol. (2002) 83:2897-2905.

[31] Ikeda T., Horiuchi M., Ishiguro N., Muramatsu Y., Kai Uwe G.D., Shinagawa M., Amino acid polymorphisms of PrP with reference to onset of scrapie in Suffolk and Corriedale sheep in Japan, J. Gen. Virol. (1995) 76:2577-2581.

[32] Iwata N., Sato Y., Higuchi Y., Nohtomi K., Nagata N., Hasegawa H., Tobiume M., Nakamura Y., Hagiwara K., Furuoka H., Horiuchi M., Yamakawa Y., Sata T., Distribution of $\operatorname{PrP}(\mathrm{Sc})$ in cattle with bovine spongiform encephalopathy slaughtered at abattoirs in Japan, Jpn. J. Infect. Dis. (2006) 59:100-107.

[33] Jackman R., Everest D.J., Schmerr M.J., Khawaja M., Keep P., Docherty J., Evaluation of a preclinical blood test for scrapie in sheep using immunocapillary electrophoresis, J. AOAC Int. (2006) 89:720-727.

[34] Jeffrey M., Gonzalez L., Espenes A., Press C.M., Martin S., Chaplin M., Davis L., Landsverk T., MacAldowie C., Eaton S., McGovern G., Transportation of prion protein across the intestinal mucosa of scrapie-susceptible and scrapie-resistant sheep, J. Pathol. (2006) 209:4-14.

[35] Jeffrey M., Gonzalez L., Classical sheep transmissible spongiform encephalopathies: pathogenesis, pathological phenotypes and clinical disease, Neuropathol. Appl. Neurobiol. (2007) 33:373-394. 
[36] Jenkins T.W., The autonomic nervous system, in: Funtional mammalian neuroanatomy, Lea \& Febiger, Philadelphia, USA, 1978, pp. 146-165.

[37] Katz J.B., Pedersen J.C., Jenny A.L., Taylor W.D., Assessment of western immunoblotting for the confirmatory diagnosis of ovine scrapie and bovine spongiform encephalopathy (BSE), J. Vet. Diagn. Invest. (1992) 4:447-449.

[38] Kimberlin R.H., Walker C.A., Pathogenesis of scrapie in mice after intragastric infection, Virus Res. (1989) 12:213-220

[39] Lacroux C., Corbiere F., Tabouret G., Lugan S., Costes P., Mathey J., Delmas J.M., Weisbecker J.L., Foucras G., Cassard H., Elsen J.M., Schelcher F., Andréoletti O., Dynamics and genetics of PrPSc placental accumulation in sheep, J. Gen. Virol. (2007) 88:1056-1061.

[40] Laplanche J.L., Chatelain J., Westaway D., Thomas S., Dussaucy M., Brugere-Picoux J., Launay J.M., PrP polymorphisms associated with natural scrapie discovered by denaturing gradient gel electrophoresis, Genomics (1993) 15:30-37.

[41] Ligios C., Sigurdson C.J., Santucciu C., Carcassola G., Manco G., Basagni M., Maestrale C., Cancedda M.G., Madau L., Aguzzi A., PrPSc in mammary glands of sheep affected by scrapie and mastitis, Nat. Med. (2005) 11:1137-1138.

[42] Mabbott N.A., Mackay F., Minns F., Bruce M.E., Temporary inactivation of follicular dendritic cells delays neuroinvasion of scrapie, Nat. Med. (2000) 6:719720 .

[43] Miller J.M., Jenny A.L., Taylor W.D., Marsh R.F., Rubenstein R., Race R.E., Detwiler L.A., Immunohistochemical detection of prion protein in sheep with scrapie, J. Vet. Diagn. Invest. (1993) 5:309316.

[44] Mishra R.S., Basu S., Gu Y., Luo X., Zou W. Q., Mishra R., Li R., Chen S. G., Gambetti P., Fujioka H., Singh N., Protease-resistant human prion protein and ferritin are cotransported across Caco- 2 epithelial cells: implications for species barrier in prion uptake from the intestine, J. Neurosci. (2004) 24:11280 11290.

[45] Mohan J., Brown K.L., Farquhar C.F., Bruce M.E., Mabbott N.A., Scrapie transmission following exposure through the skin is dependent on follicular dendritic cells in lymphoid tissues, J. Dermatol. Sci. (2004) 35:101-111

[46] Mohri S., Farquhar C.F., Somerville R.A., Jeffrey M., Foster J.D., Hope J., Immunodetection of a disease specific PrP fraction in scrapie- affected sheep and BSE-affected cattle, Vet. Rec. (1992) 131:537-539.

[47] Muramatsu Y., Onodera A., Horiuchi M., Detection of PrPsc in sheep at the preclinical stage of scrapie and its significance for the diagnosis of insidious infection, Arch. Virol. (1994) 134:427-432.
[48] Neutra M.R., Pringault E., Kraehenbuhl J.P., Antigen sampling across epithelial barriers and induction of mucosal immune responses, Annu. Rev. Immunol. (1996) 14:275-300.

[49] Onodera T., Ikeda T., Muramatsu Y., Shinagawa M., Isolation of scrapie agent from the placenta of sheep with natural scrapie in Japan, Microbiol. Immunol. (1993) 37:311-316.

[50] Outram G.W., The pathogenesis of scrapie in mice, in: Kimberlin R.H. (Ed.), Slow virus diseases of animals and man, North Holland Publishing Company, Amsterdam, the Netherlands, 1976, pp. 325-357.

[51] Pattison I.H., Hoare M.N., Jebbett J.N., Watson W.A., Spread of scrapie to sheep and goats by oral dosing with foetal membranes from scrapie-affected sheep, Vet. Rec. (1972) 90:465-468.

[52] Race R.E., Ernst D.R., Jenny A.L., Taylor W.D., Sutton D., Caughey B., Diagnostic implications of detection of proteinase K-resistant protein in spleen, lymph nodes, and brain of sheep, Am. J. Vet. Res. (1992) 53:883-889.

[53] Race R.J., Jenny A.L., Sutton D., Scrapie infectivity and proteinase K-resistant prion protein in sheep placenta, brain, spleen, and lymph node: implications for transmission and antemortem diagnosis, J. Infect. Dis. (1998) 178:949-953.

[54] Rescigno M., Rotta G., Valzasina B., Ricciardi Castagnoli P., Dendritic cells shuttle microbes across gut epithelial monolayers, Immunobiology (2001) 204:572-581.

[55] Rescigno M., Urbano M., Valzasina B., Francolini M., Rotta G., Bonasio R., Granucci F., Kraehenbuhl J.P., Ricciardi Castagnoli P., Dendritic cells express tight junction proteins and penetrate gut epithelial monolayers to sample bacteria, Nat. Immunol. (2001) 2:361-367.

[56] Ryder S., Dexter G., Bellworthy S., Tongue S., Demonstration of lateral transmission of scrapie between sheep kept under natural conditions using lymphoid tissue biopsy, Res. Vet. Sci. (2004) 76:211-217.

[57] Schmerr M.J., Jenny A.L., Bulgin M.S., Miller J.M., Hamir A.N., Cutlip R.C., Goodwin K.R., Use of capillary electrophoresis and fluorescent labeled peptides to detect the abnormal prion protein in the blood of animals that are infected with a transmissible spongiform encephalopathy, J. Chromatogr. A (1999) 853:207-214.

[58] Scott J.R., Foster J.D., Fraser H., Conjunctival instillation of scrapie in mice can produce disease, Vet. Microbiol. (1993) 34:305-309.

[59] Siso S., Gonzalez L., Jeffrey M., Martin S., Chianini F., Steele P., Prion protein in kidneys of scrapie-infected sheep, Vet. Rec. (2006) 159:327-328.

[60] Somerville R.A., Birkett C.R., Farquhar C.F., Hunter N., Goldmann W., Dornan J., Grover D., Hennion R.M., Percy C., Foster J.D., Jeffrey M., 
Immunodetection of PrPSc in spleens of some scrapieinfected sheep but not BSE-infected cows, J. Gen. Virol. (1997) 78:2389-2396.

[61] Taylor D.M., McConnell I., Fraser H., Scrapie infection can be established readily through skin scarification in immunocompetent but not immunodeficient mice, J. Gen. Virol. (1996) 77:1595-1599.

[62] Telling G.C., Prion protein genes and prion diseases: studies in transgenic mice, Neuropathol. Appl. Neurobiol. (2000) 26:209-220.

[63] Terry L.A., Marsh S., Ryder S.J., Hawkins S.A., Wells G.A., Spencer Y.I., Detection of disease-specific PrP in the distal ileum of cattle exposed orally to the agent of bovine spongiform encephalopathy, Vet. Rec. (2003) 152:387-392.

[64] Van Keulen L.J.M., Schreuder B.E.C., Meloen R.H., Mooij-Harkes G., Poelen-van den Berg M., Vromans M.E.W., Langeveld J.P.M., Immunohistochemical detection and localization of prion protein in brain tissue of sheep with natural scrapie, Vet. Pathol. (1995) 32:299-308.

[65] Van Keulen L.J.M., Schreuder B.E.C., Meloen R.H., Mooij-Harkes G., Vromans M. E.W., Langeveld J.P.M., Immunohistochemical detection of prion protein in lymphoid tissues of sheep with natural scrapie, J. Clin. Microbiol. (1996) 34:1228-1231.

[66] Van Keulen L.J.M., Schreuder B.E.C., Vromans M.E.W., Langeveld J.P.M., Smits M.A., Scrapieassociated prion protein in the gastro-intestinal tract of sheep with natural scrapie, J. Comp. Pathol. (1999) 121:55-63.

[67] Van Keulen L.J.M., Schreuder B.E., Vromans M.E., Langeveld J.P., Smits M.A., Pathogenesis of natural scrapie in sheep, Arch. Virol. Suppl. (2000) 16:57-71.

[68] Van Keulen L.J.M., Vromans M.E.W., van Zijderveld F.G., Early and late pathogenesis of natural scrapie infection in sheep, APMIS (2002) 110:23-32.

[69] Vascellari M., Nonno R., Mutinelli F., Bigolaro M., Di Bari M.A., Melchiotti E., Marcon S., D’Agostino C., Vaccari G., Conte M., De Grossi L., Rosone F., Giordani F., Agrimi U., PrPSc in salivary glands of scrapie-affected sheep, J. Virol. (2007) 81:4872-4876.
[70] Wells G.A.H., Scott A.C., Johnson C.T., Gunning R.F., Hancock R.D., Jeffrey M., Bradley R., Dawson M., A novel progressive spongiform encephalopathy in cattle, Vet. Rec. (1987) 121:419-420.

[71] Wells G.A.H., Dawson M., Hawkins S.A.C., Green R.B., Dexter I., Francis M.E., Simmons M.M., Austin A.R., Horigan M.W., Infectivity in the ileum of cattle challenged orally with bovine spongiform encephalopathy, Vet. Rec. (1994) 135:40-41.

[72] Wells G.A.H., Dawson M., Hawkins S.A.C., Austin A.R., Green R.B., Dexter I., Horigan M.W., Simmons M.M., Preliminary observations on the pathogenesis of experimental bovine spongiform encephalopathy, in: Gibbs C.J.J. (Ed.), Sixth International Workshop on bovine spongiform encephalopathy: the BSE dilemma, Springer-Verlag, New York, USA, 1996, pp. 28-44.

[73] Wells G.A.H., Hawkins S.A.C., Green R.B., Austin A.R., Dexter I., Spencer Y.I., Chaplin M.J., Stack M.J., Dawson M., Preliminary observations on the pathogenesis of experimental bovine spongiform encephalopathy (BSE): an update, Vet. Rec. (1998) 142:103-106.

[74] Wells G.A.H., Spiropoulos J., Hawkins S.A., Ryder S.J., Pathogenesis of experimental bovine spongiform encephalopathy: preclinical infectivity in tonsil and observations on the distribution of lingual tonsil in slaughtered cattle, Vet. Rec. (2005) 156:401407.

[75] Wilesmith J.W., Wells G.A.H., Cranwell M.P., Ryan J.B.M.M., Bovine spongiform encephalopathy: epidemiological studies, Vet. Rec. (1988) 123:638644.

[76] Wilesmith J.W., Origins of BSE, Vet. Rec. (1991) 128:310.

[77] Wilesmith J.W., Ryan J.B.M., Atkinson M.J., Bovine spongiform encephalopathy: epidemiological studies on the origin, Vet. Rec. (1991) 128:199-203.

[78] Wrathall A.E., Brown K.F.D., Sayers A.R., Wells G.A.H., Simmons M.M., Farrelly S.S.J., Bellerby P., Squirrell J., Spencer Y.I., Wells M., Stack M. J., Bastiman B., Pullar D., Scatcherd J., Heasman L., Parker J., Hannam D.A.R., Helliwell D.W., Chree A., Fraser H., Studies of embryo transfer from cattle clinically affected by bovine spongiform encephalopathy (BSE), Vet. Rec. (2002) 150:365-378. 